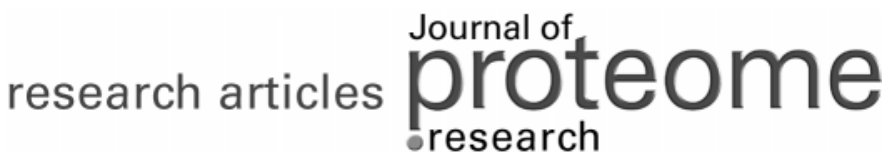

\section{Probing Cysteine Reactivity in Proteins by Mass Spectrometric EC-Tagging}

\author{
Loïc Dayon, Christophe Roussel, and Hubert H. Girault* \\ Laboratoire d'Electrochimie Physique et Analytique, Ecole Polytechnique Fédérale de Lausanne (EPFL),
} CH-1015 Lausanne, Switzerland

Received October 28, 2005

\begin{abstract}
The on-line electrochemical tagging (EC-tagging) of cysteine residues in proteins during mass spectrometry is studied to probe the cysteine environment. Benzoquinone probes electrogenerated at a microspray electrode react with the thiol functions of the proteins within a microchannel and the products are analyzed by mass spectrometry. The fundamentals of the technique are discussed, with a focus on the kinetic aspects. The EC-tagging efficiency of the cysteine residues in proteins is used to probe their environment. Experiments with unmodified proteins and their chemically reduced forms highlight the strong effect of the cysteine site reactivity on the tagging efficiencies. This study highlights relevant parameters for such on-line electrochemical derivatization/MS detection strategies.
\end{abstract}

Keywords: cysteine markers • electrochemistry • electrospray • mass spectrometry • protein structures probing

\section{Introduction}

In proteins, cysteine residues are important for metal coordination, catalysis, and protein structure by forming disulfide bonds. Moreover, crucial cysteine residues are involved in modulation of protein activity and signaling events via redox reactions, chelation of transition metals and $S$-nitrosation. Cysteine is also the binding site in human albumin for biological and clinical small molecules such as platinum(II) anticancer drugs. ${ }^{1,2}$

The reactivity of cysteine in proteins is complex for reasons such as steric hindrance, charge distribution and solvation. It varies from one protein to another and specific competition with glutathione makes the system even more complex in biological fluids. The antioxidant character of cysteinyl proteins depends highly on the protein structure that for instance prevent the formation of disulfide bonds in albumin or reduce the antioxidant capacity of hemoglobin in comparison to glutathione..$^{3,4}$

As nucleophiles, thiols have a reaction rate that depends on the protonation state of the sulfhydryl group. The primary structure of the biomolecule influences the thiol reactivity since the $\mathrm{p} K_{\mathrm{a}}$ of the thiol is strongly dependent on the charged residues in the vicinity of the cysteine. It has been shown that Michael-type addition of sulfhydryl-containing peptides onto unsaturated groups have higher or lower rates when positive charges and negative charges are respectively in the vicinity, resulting to a decrease or an increase of $\mathrm{p} K_{\mathrm{a}}{ }^{5}$

In electrospray ionization (ESI) mass spectrometry (MS), the application of an electric field to generate the spray has led to the consideration of emitters as on-line electrochemical

* To whom correspondence should be addressed. Fax (+41) 21-693-3667. E-mail: hubert.girault@epfl.ch.

10.1021/pr050365o CCC: $\$ 33.50$ @ 2006 American Chemical Society flow-cells. Then, the inherent electrochemical aspect of electrospray ${ }^{6-8}$ has opened the way to the study of electrochemically induced reactions ${ }^{9-12}$ like rearrangements of biological molecules. ${ }^{13-15}$ Moreover, electro-active probes have been developed to chemically derivatize weakly ionisable compounds, ${ }^{16-21}$ and to label specific amino acids. ${ }^{22}$ Recently, we have developed a polymer micro-ESI emitter comprised of a microband electrode. ${ }^{23}$ This micro-flow-cell was shown to be an efficient controlled-current electrochemical flow-cell compared to many commercially available ESI sources. ${ }^{24}$ Additionally, the upstream position of the microband electrode within the micromachined flow channel is a major advantage in the electrogeneration of tags to bind to molecules flowing above the electrode toward the Taylor cone. The oxidation of hydroquinone derivatives on the microband anode was studied to tag cysteine residues in peptides via a selective 1,4Michael addition. When controlling both the electrode mass transport and the kinetics of the addition reaction, the application of on-line counting of cysteines in peptides to the identification of proteins by peptide mass mapping was achieved..$^{25,26}$

We present here a method to probe cysteinyl sites in proteins. An analytical kinetic model is developed to predict tagging extents at the end of the microchannel prior to the Taylor cone. We show that the MS measurements of the extent of the EC-tagging reaction depend mainly on the reactivity of cysteine residues in the proteins and not on the ionization properties of adducts. The EC-tagging of $\beta$-lactoglobulin A (one free cysteine residue) was studied and compared with the multi-tagging of its reduced form (i.e., five free cysteine residues after reduction of the two disulfide bonds). Creatine phosphokinase and reduced insulin were probed by EC-tagging to complete the study.

Journal of Proteome Research 2006, 5, 793-800 793 Published on Web 02/21/2006 


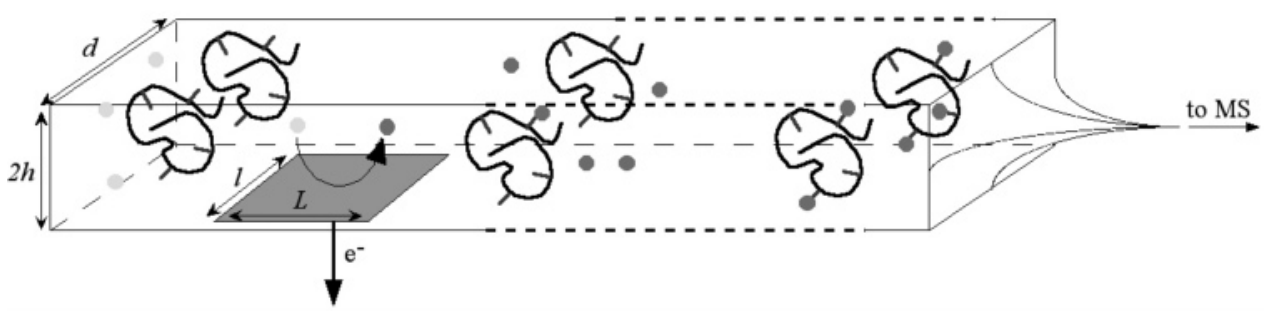

Figure 1. Schematic representation of the EC-tagging of cysteinyl proteins (P) by benzoquinone (BQ, dark dot) tags electrogenerated at the microspray electrode from hydroquinone ( $\mathrm{HQ}$, clear dot).

\section{Experimental Section}

Maple Calculation. The kinetic model is based on a set of differential equations that can be solved analytically with commercial software (Maple 9.5, Waterloo Maple Inc.) on an iMac G5 (2GHz PowerPC, 512MB DDR400 SDRAM) (see Supporting Information).

Materials. Insulin from bovine pancreas, creatine phosphokinase (CK) from rabbit muscle and $\beta$-lactoglobulin A from bovine milk ( $>90 \%$ ) were purchased from Sigma (St Louis, MO). Tri- $n$-butylphosphine (TBP, 97\%) and methoxycarbonyl-1,4hydroquinone (methyl 2,5-dihydroxybenzoate) (99\%) were from Aldrich (Milwaukee, WI). 1,4-Hydroquinone (> 98\%), 1,4benzoquinone ( $\geq 98 \%$ ), L-cysteine $(>99.5 \%)$, lithium trifluoromethanesulfonate (purum), $\mathrm{N}, \mathrm{N}$-dimethylformamide (DMF, $\sim 99 \%$ ), acetic acid (AcOH, 99.5\%) were from Fluka (Büchs, Switzerland). Methanol (MeOH, > 99.8\%) was bought from Riedel-de Haën (Seelze, Germany). Acetonitrile (HPLC grade) was from Sds (Peypin, France). Deionized water $(18.2 \mathrm{M} \Omega \cdot \mathrm{cm})$ was prepared using a Milli-Q system from Millipore (Bedford, MA).

Methoxycarbonyl-1,4-benzoquinone was synthesized as already described. ${ }^{27}$

Reduction of Proteins. To reduce the disulfide bridges, 1 mg of purified protein was dissolved in $900 \mu \mathrm{L}$ of $\mathrm{H}_{2} \mathrm{O} .100 \mu \mathrm{L}$ of TBP at $10 \%$ in DMF $\left(4 \cdot 10^{-5} \mathrm{~mol}\right)$ was added to the protein solution according to the literature. ${ }^{28}$ The mixture was stirred between 60 and $90 \mathrm{~min}$. Then, the resulting mixture was lyophilized overnight to get rid of the excess reagent (TBP) ${ }^{29}$ that can react with benzoquinone compounds. ${ }^{30}$ Without lyophilization, the EC-tagging of the protein was indeed not obtained. The proteins were redissolved in degassed $\mathrm{MeOH} /$ $\mathrm{H}_{2} \mathrm{O} / \mathrm{AcOH} 50 / 49 / 1$.

EC-Tagging. The proteins at $50 \mu \mathrm{M}$ were sprayed with methoxycarbonyl-1,4-hydroquinone or 1,4-hydroquinone at 2.5 $\mathrm{mM}$ in degassed $\mathrm{MeOH} / \mathrm{H}_{2} \mathrm{O} / \mathrm{AcOH} 50 / 49 / 1$. The total acquisition time of the spectra was $1 \mathrm{~min}$. A few minutes were needed to reach the steady state of the process. The EC-tagging was checked to be stable during $25 \mathrm{~min}$.

The apparent tagging extents (a-TE\%) and the MS tagging yield $\left(\right.$ Yield $_{\mathrm{MS}}$ ) were calculated as 100 fold the sum of the peak intensity of the product(s) over the sum of the peak intensity of the product(s) and the starting protein.

Chemical Labeling and Ionization Experiments. The chemical formation of adducts was performed by adding benzoquinone BQ as a solid or in acetronitrile solution (from 250 to $2500 \mu \mathrm{M})$. The ratio $\mathrm{BQ} /$ protein or cysteine was varied from 0.05 to 0.7 . The mixtures were analyzed by MS after $30-45 \mathrm{~min}$ of reaction. The reaction is rapid and is assumed to be total ${ }^{27,31}$ to calculate the yields (Yield $\mathrm{MS}_{\mathrm{MS}}$ ) as 100 fold the sum of the peak intensity of the product(s) over the sum of the peak intensity of the product(s) and the starting protein.
Micro-Fabricated ESI Emitter. The polymer microspray fabrication has been already described in detail. ${ }^{23}$ The surface of the electrode integrated at the bottom of the channel was $70 \times 25 \mu \mathrm{m}^{2}$ (the length $L$ was $70 \mu \mathrm{m}$, and the width $l$ was 25 $\mu \mathrm{m})$. The channel length from the electrode to the tip was $L_{\mathrm{ch}}$ $=2 \mathrm{~cm}$ and the cross-section was $30 \times 35 \mu \mathrm{m}^{2}$ (the width $d$ was $30 \mu \mathrm{m}$ and the height $2 h$ was $35 \mu \mathrm{m}$ ).

MS Setup. A LCQ DUO ion trap mass spectrometer (Finnigan, San José, CA) was used. The heated capillary was kept at $200{ }^{\circ} \mathrm{C}$. In each experiment, the ion transmission parameters were optimized automatically in order to improve the detection of the analyte of interest (the unmodified biomolecule). The ESI interface was removed, and the microchip holder was mounted on the probe slide adapter of the mass spectrometer. The device was coupled to a syringe pump (kdScientific, Holliston, MA) to introduce the solution. The flow rate $F_{\mathrm{v}}$ was set to $250 \mathrm{~nL} \cdot \mathrm{min}^{-1}$ and the voltage applied was $3-4 \mathrm{kV}$. The distance from the outlet of the microchip to the entrance of the spectrometer varied between 1 and $2 \mathrm{~cm}$ in order to set the electrospray current and to optimize the signal and the trap injection time. The applied spray current $I_{\text {spray }}$ was set at 120 nA.

Diffusion Coefficient Measurements. The electrochemical measurements were recorded on an Autolab PGSTAT 12 potentiostat from Metrohm (Herisau, Switzerland) using an undivided cell filled with a protected saturated calomel electrode as reference electrode, a glassy carbon electrode $(3 \mathrm{~mm}$ diameter) as working electrode and a platinum wire as counter electrode. The electrochemical cell was filled with the spray solution $\left(\mathrm{MeOH} / \mathrm{H}_{2} \mathrm{O} / \mathrm{AcOH} 50 / 49 / 1\right)$ at $0.1 \mathrm{M}$ lithium trifluoromethanesulfonate and $2 \mathrm{mM}$ hydroquinone. The working electrode was carefully polished with a suspension of $0.3 \mu \mathrm{m}$ alumina (from Buehler, Lake Bluff, IL) before every experiment. Diffusion coefficients of 1,4-hydroquinone and methoxycarbonyl-1,4-hydroquinone were measured by chronoamperometry. The potential was set for $60 \mathrm{~s}$ at $0.8 \mathrm{~V}$ and at 1 $\mathrm{V}$ for 1,4-hydroquinone and methoxycarbonyl-1,4-hydroquinone respectively and the oxidation current was recorded (every $0.5 \mathrm{~s})$. Diffusion coefficients were extracted from the slope of the straight line $I(t)=f\left(t^{-0.5}\right)$ and were found to be $4 \times 10^{-10}$ and $3.5 \times 10^{-10} \mathrm{~m}^{2} \cdot \mathrm{s}^{-1}$ for 1,4-hydroquinone and methoxycarbonyl-1,4-hydroquinone. This difference can be attributed to the strong hydration of 1,4-hydroquinone in water compared to that of methoxycarbonyl-1,4-hydroquinone.

\section{Results and Discussion}

1. Mechanism and Kinetics. Figure 1 shows a schematic representation of a microchip electrospray emitter comprising basically a flow channel and a band electrode located at the bottom of the microchip. During electrospray from the microchip at a flow rate $F_{\mathrm{V}}$ of $250 \mathrm{~nL} \cdot \mathrm{min}^{-1}$, benzoquinone tags (BQ) 
Scheme 1. EC-Tagging Mechanism of a Cysteinyl Protein with Methoxycarbonyl-1,4- Hydroquinone

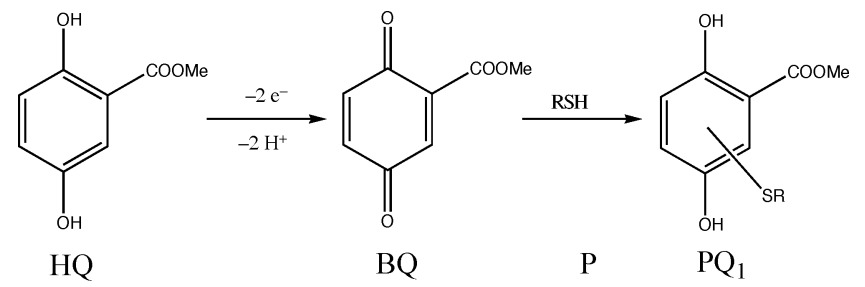

are generated at a microband electrode by oxidation of hydroquinone compounds (HQ) and react specifically with the thiol groups of the proteins (P) in the flow channel (Scheme $1)$. The products of the reaction at the end of the channel are analyzed continuously by ion trap mass spectrometry.

The addition of BQ tags on thiols has a very large equilibrium constant. ${ }^{27,31}$ According to the number of cysteines $\mathrm{n}$ in $\mathrm{P}$, adducts $\left(\mathrm{PQ}_{i}\right)$ are successively formed $(i=1 \ldots \mathrm{n})$ (Scheme 2$)$. The mechanism for multi-cysteine-containing protein can be described by $\mathrm{PQ}_{i}$ are that representative of the tagged state but not of a defined molecule (i.e., for multi-cysteine-containing protein, $\mathrm{PQ}_{1}$ represents several regio-isomers). It is assumed that every thiol group presents equal reactivity.

1.1. Analytical Kinetic Model. 1.1.1. Electrochemical Step. In the positive ionization mode, the reaction taking place at the high voltage microband electrode ${ }^{32}$ as illustrated in Figure 1 is the oxidation of HQ considering its redox potential. ${ }^{27}$ In the flow-cell microspray emitter, the convection-diffusion limiting current $I_{\text {lim }}$ in a 2-D laminar Poisseuille flow can be classically calculated by ${ }^{33-35}$

$$
I_{\lim }=0.925 z F C l(L D)^{2 / 3}\left(\frac{F_{V}}{h^{2} d}\right)^{1 / 3}
$$

where $z$ is the number of electrons per oxidized molecule, $F$ is the Faraday constant, $C$ and $D$ are respectively the bulk concentration and the diffusion coefficient of the electroactive species, $l$ and $L$ the width and the length of the electrode, $F_{\mathrm{V}}$ the pressure-driven flow rate, $2 h$ and $d$ the height and the width of the channel.

The electrospray current $I_{\text {spray }}$ is set by controlling the flow rate, the distance between the chip tip and the entrance of the MS, and the high voltage applied by the $\mathrm{MS}^{8}$ (see Experimental Section). When the imposed electrospray current $I_{\text {spray }}$ value is greater than the calculated HQ oxidation convection-diffusion limiting current $I_{\text {lim }}$, we can use Faraday's law to calculate the quantity of BQ tags produced at the electrode according to

$$
N_{\mathrm{BQ}}=\frac{I_{\mathrm{lim}} t_{\mathrm{e}}}{z F}
$$

where $t_{\mathrm{e}}=L / \overline{\boldsymbol{v}}$ is the residence time of species on the top of the electrode and $\bar{v}$ is the mean flow velocity.

Conversely, when the imposed electrospray current $I_{\text {spray }}$ value is lower than the calculated HQ oxidation current $I_{\text {lim }}$, the quantity of BQ tags produced at the electrode is

$$
N_{\text {BQ }}=\frac{I_{\text {spray }} t_{\mathrm{e}}}{z F}
$$

Considering a fast transversal diffusion above the electrode, the initial concentration of BQ tags $\left([\mathrm{BQ}]_{0}\right)$ can be assimilated to its mean concentration in the volume element over the electrode $\left(V_{\mathrm{e}}=L \times d \times 2 h\right)$ after a time $t_{\mathrm{e}}$ (Table 1 and Figure
Scheme 2

$$
\begin{aligned}
& \mathrm{P}+\mathrm{BQ} \stackrel{k_{1}=\mathrm{n} k}{\longrightarrow} \mathrm{PQ}_{1} \\
& \mathrm{PQ}_{1}+\mathrm{BQ} \stackrel{k_{2}=(\mathrm{n}-1) k}{\longrightarrow} \mathrm{PQ}_{2} \\
& \vdots \\
& \mathrm{PQ}_{\mathrm{n}-1}+\mathrm{BQ} \stackrel{k_{\mathrm{n}}=k}{\longrightarrow} \mathrm{PQ}_{\mathrm{n}}
\end{aligned}
$$

Table 1. Parameters ${ }^{a}$ for Calculation of Species Concentration in the Channel (N.B. $I_{\text {spray }}=120 \mathrm{nA}$ )

\begin{tabular}{lll}
\hline general parameters & \multicolumn{1}{c}{1,4 -Hydroquinone } & \multicolumn{1}{c}{$\begin{array}{c}\text { Methoxycarbonyl-1,4- } \\
\text { hydroquinone }\end{array}$} \\
\hline$F_{\mathrm{V}}=250 \mathrm{~nL} \cdot \mathrm{min}^{-1}$ & $D=4 \cdot 10^{-10} \mathrm{~m}^{2} \cdot \mathrm{s}^{-1 b}$ & $D=3.5 \cdot 10^{-10} \mathrm{~m}^{2} \cdot \mathrm{s}^{-1 b}$ \\
$\overline{\boldsymbol{v}}=4.3 \mathrm{~mm} \cdot \mathrm{s}^{-1}$ & $I_{\mathrm{lim}}=81 \mathrm{nA}^{c}$ & $I_{\mathrm{lim}}=74 \mathrm{nA}^{c}$ \\
{$[\mathrm{HQ}]_{0}=2.5 \mathrm{mM}$} & {$[\mathrm{BQ}]_{0}=101 \mu \mathrm{M}^{d}$} & {$[\mathrm{BQ}]_{0}=93 \mu \mathrm{M}^{d}$}
\end{tabular}

${ }^{a}$ The real cross-section geometry of the channel is in fact trapezoidal. ${ }^{32}$ To bring this correction to the model, the width of the channel $d$ was taken as $d_{\mathrm{m}}=(d+l) / 2$. The reaction time $t$ in the full channel is then $4.7 \mathrm{~s} .{ }^{b}$ See Experimental Section. ${ }^{c}$ According to eq $1 .{ }^{d}$ According to eq 2.

1). Post-electrode oxidation of HQ by the other species electrogenerated at the electrode such as oxygen is neglected.

1.1.2. Chemical Step. For a simplified analytical calculation of the extent of tagging in the microchip setup, complete mixing is assumed to be ideal in the finite volume $V_{e}$. The reaction occurs in this volume translating with the flow along the microchannel.

In the case of the simplest addition between BQ tags and a protein $\mathrm{P}$ containing one cysteine the rate law follows a firstorder kinetics for each reactant: ${ }^{36,37}$

$$
v=-\frac{\mathrm{d}[\mathrm{BQ}]}{\mathrm{d} t}=-\frac{\mathrm{d}[\mathrm{P}]}{\mathrm{d} t}=\frac{\mathrm{d}\left[\mathrm{PQ}_{1}\right]}{\mathrm{d} t}=k[\mathrm{BQ}][\mathrm{P}]
$$

$v$ is the rate of the reaction, $k$ is the rate constant and [BQ], $[\mathrm{P}]$, and $\left[\mathrm{PQ}_{1}\right]$ represent respectively the concentration of the electrogenerated BQ tags, the concentration of a protein $\mathrm{P}$ containing one cysteine residue and the concentration of the single-cysteine-containing product $\mathrm{PQ}_{1}$ at the time $t$. The integrated rate law gives

$$
\frac{1}{[\mathrm{BQ}]_{0}-[\mathrm{P}]_{0}} \ln \left[\frac{[\mathrm{P}]_{0}\left([\mathrm{BQ}]_{0}-x\right)}{[\mathrm{BQ}]_{0}\left([\mathrm{P}]_{0}-x\right)}\right]=k t
$$

where $[\mathrm{BQ}]_{0}$ and $[\mathrm{P}]_{0}$ are the initial concentrations of the electrogenerated $\mathrm{BQ}$ tags (i.e., at the electrode) and of the single-cysteine-containing protein (Scheme 2), and $x=\left[\mathrm{PQ}_{1}\right]$ $=[\mathrm{BQ}]_{0}-[\mathrm{BQ}]=[\mathrm{P}]_{0}-[\mathrm{P}]$.

This calculation can be applied to the consecutive stages when the protein possesses several cysteine units (Scheme 2). The use of the Maple software is then convenient to solve the differential equation systems, as the analytical solutions are too cumbersome to derive manually (see the program for a fivestep chemical reaction, i.e. five-cysteine-containing protein, in the Supporting Information).

1.2. Numerical Validation of the Model. Recently, we have developed a finite-element model treating the emitter as a flow chemical reactor to study the consecutive reactions in the microchannel and to optimize the conditions for cysteine counting in peptides. ${ }^{38}$ The comparison of the concentrations $[B Q],[P]$, and $\left[\mathrm{PQ}_{n}\right]$ at the end of the channel from the analytical kinetic model shows a very good correlation with the simulated data, validating the present analytical kinetic model as illustrated in Figure 2 for methoxycarbonyl-1,4-hydroquinone. 

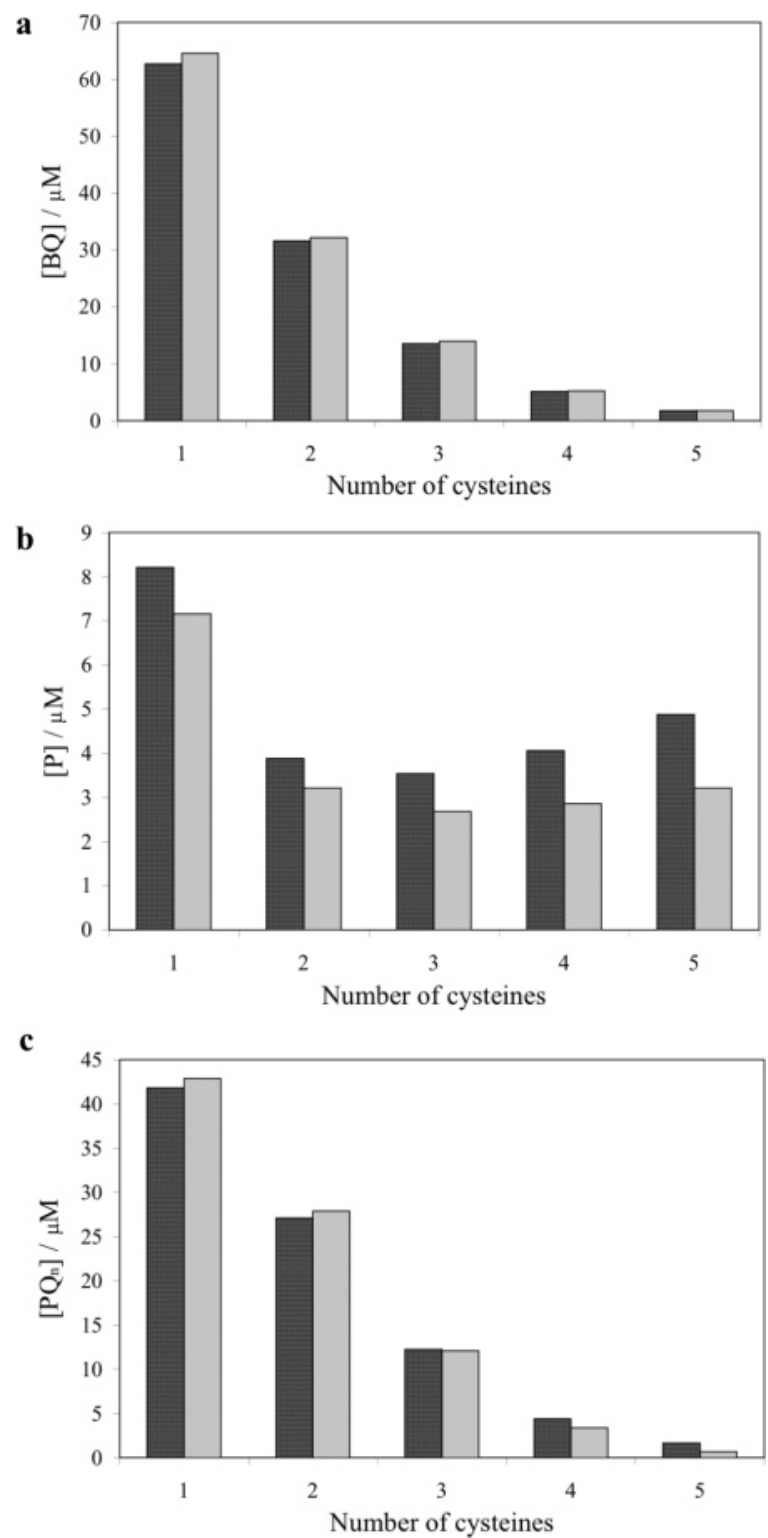

Figure 2. Analytical model validation. The concentration of benzoquinone $\mathrm{BQ}(\mathbf{a})$, protein $\mathrm{P}(\mathbf{b})$ and fully tagged product $\mathrm{PQ}_{n}$ (c) were calculated from single-cysteine-containing to fivecysteine-containing protein by numerical simulation for a $2 \mathrm{D}$ cross section of the channel geometry ${ }^{38}$ (black bars) and by analytical kinetic model (grey bars for $[\mathrm{BQ}]_{0}=107 \mu \mathrm{M},[\mathrm{P}]_{0}=50$ $\mu \mathrm{M}, k=5000 \mathrm{M}^{-1} \cdot \mathrm{s}^{-1}$ and $t=5 \mathrm{~s}$ corresponding to a rectangular channel geometry with $I=d=30 \mu \mathrm{m})$.

1.3. Experimental Validation of the Model. Tagging of L-cysteine $\left([\mathrm{P}]_{0}=200 \mu \mathrm{M}\right)$ by methoxycarbonyl-1,4-hydroquinone $\left([\mathrm{HQ}]_{0}=20 \mathrm{mM}\right)$ has been previously investigated and the Michael addition rate constant has be determined to be very large in the spray medium $\mathrm{MeOH} / \mathrm{H}_{2} \mathrm{O} / \mathrm{AcOH} 50 / 49 / 1 . .^{27,37}$ The apparent EC-tagging extent, a-TE\% was $99 \%$. To take into account MS ionization phenomena induced by the tag, ${ }^{10,39}$ a calibration curve was determined giving the MS response as a function of the true mixture composition (Figure 3). The effective e-TE\% (i.e., in bulk) extracted from the curve is $76 \%$.

The analytical kinetic model predicts a $67 \%$ TE\% value for tagging with methoxycarbonyl-1,4-hydroquinone, which correlates rather well with experimental e-TE\% of $76 \%$. These data



Figure 3. Calibration curves of the MS tagging yield (Yield $\mathrm{MS}_{\mathrm{MS}}$ ) as a function of the bulk yield (Yield ${ }_{\text {true }}$ ) for the reaction of L-cysteine with methoxycarbonyl-1,4-benzoquinone. The mixtures were prepared by adding $\mathrm{BO}$ equivalent (from 0.25 to 0.7 ) to $200 \mu \mathrm{M}$ of L-cysteine. The fitting equation is $Y=92.68+$ $0.083514 X$

Table 2. Tagging Extent Obtained by Calculation and MS Experiments for a Single-cysteine-containing Biomolecule ${ }^{a}$

\begin{tabular}{|c|c|c|c|c|}
\hline \multirow[b]{2}{*}{$\begin{array}{l}\text { Hydroquinone } \\
\text { compound }\end{array}$} & \multirow[b]{2}{*}{$k_{\mathrm{cys}}\left(\mathrm{M}^{-1} \cdot \mathrm{s}^{-1}\right)^{b}$} & \multicolumn{3}{|c|}{ tagging extent (\%) } \\
\hline & & $\begin{array}{l}\text { analytical } \\
\mathrm{TE}^{c}\end{array}$ & $\begin{array}{l}\text { apparent } \\
\text { a-TE\% }^{d}\end{array}$ & $\begin{array}{l}\text { effective } \\
\text { e-TE\% }{ }^{d}\end{array}$ \\
\hline $\begin{array}{l}\text { Methoxycarbonyl-1,4- } \\
\text { hydroquinone }\end{array}$ & 5000 & 79 & 31 & 26 \\
\hline 1,4-Hydroquinone & 210 & 9 & 25 & 5 \\
\hline
\end{tabular}

validate the use of the analytical kinetic model to predict the tagging efficiency.

2. EC-Tagging of Proteins. The analytical kinetic model for EC-tagging has been applied to the study of $\beta$-lactoglobulin A tagged by methoxycarbonyl-1,4-benzoquinone. This tag has been shown to be efficient because of its reactivity and the stability of its associated hydroquinone form, even in the presence of oxygen. ${ }^{27}$ It is therefore an ideal probe to tag cysteine in proteins and the physical parameters relative to the tag are given in Table 1. The tagging extent TE\% (Table 2) predicted by the kinetic model for a singly cysteinyl biomolecule is calculated using the rate constant measured for the tagging of L-cysteine, $\left(\mathrm{TE} \%=100 \cdot\left[\mathrm{PQ}_{1}\right] /\left([\mathrm{P}]+\left[\mathrm{PQ}_{1}\right]\right)=100 \cdot\right.$ $\left.\left[\mathrm{PQ}_{1}\right] /[\mathrm{P}]_{0}\right)$.

From one point of view, short residence times in the microchannel are required to avoid the reaction running to completion, so that simultaneous MS detection of both the untagged and tagged proteins can be obtained with a mass shift corresponding to the mass of the benzoquinone tags.

The apparent experimental a-TE\% (i.e., the consumption of P) for the EC-tagging of $\beta$-lactoglobulin A (one free cysteine) by methoxycarbonyl-1,4-hydroquinone at a concentration ratio of $50 \mu \mathrm{M} / 2.5 \mathrm{mM}$ was found to be $31 \%$. The mass spectrum obtained is given in Figure 4. In comparison with the analytical model (Table 2), methoxycarbonyl-1,4-hydroquinone provides a much lower conversion than expected $(31 \pm 10 \%$ a-TE\% 



Figure 4. Microspray mass spectrum of $\beta$-lactoglobulin $\mathrm{A}(50 \mu \mathrm{M})$ infused with methoxycarbonyl-1,4-hydroquinone $(2.5 \mathrm{mM})(\mathrm{a})$. Deconvolution mass spectrum (b). Grey bars give the predicted distribution of the species according to the analytical model. $P$ and $\mathrm{PQ}_{1}$ indicate respectively the untagged and tagged protein.

instead of $79 \%$ by calculation). This decrease in the reactivity of the addition reaction compared to that of the simple amino acid can be explained by several factors including difference in ionizations, variation of the local $\mathrm{p} K_{\mathrm{a}}$ in proteins and steric hindrance. ${ }^{40}$

2.1. Ionization Effects. The tag can induce a difference in MS ionization efficiency. However, the mass spectrum of an equimolar mixture of $\beta$-lactoglobulin $\mathrm{A}$ and its tagged analogue shows a signal enhancement for the tagged compound over that of the untagged protein (see Supporting Information Figure $\mathrm{S} 1)$. This effect is similar to that observed in Figure 3 for L-cysteine.

Calibration curves of the MS response as a function of a known mixture of $\beta$-lactoglobulin A and its associate adduct were carried out (Figure 5) and an effective e-TE\% of $26 \%$ was determined.

Therefore, the observed decrease of the tagging efficiency for $\beta$-lactoglobulin A cannot be attributed to a difference in ionization.

2.2. Variation of $\mathbf{p} K_{a}$ and Steric Hindrance. The thiol $\mathrm{p} K_{\mathrm{a}}$ is influenced by the peptidic chain primary structure. ${ }^{41}$ At a given $\mathrm{pH}$, a decrease or an increase of the $\mathrm{p} K_{\mathrm{a}}$ lead respectively to an increase or a decrease in the observed addition rate according to the Bronsted equation

$$
k=\left(10^{\mathrm{p} K_{\mathrm{a}}-\mathrm{pH}}+1\right)^{-1} k_{\text {true }}
$$

where $k_{\text {true }}$ is the rate constant when the thiol is fully deprotonated. ${ }^{5,42}$

According to eq 5 , the e-TE\% of $26 \%$ yields an observed rate constant $k=k_{\mathrm{P}}=760 \mathrm{M}^{-1} \cdot \mathrm{s}^{-1}$ for the free cysteine of

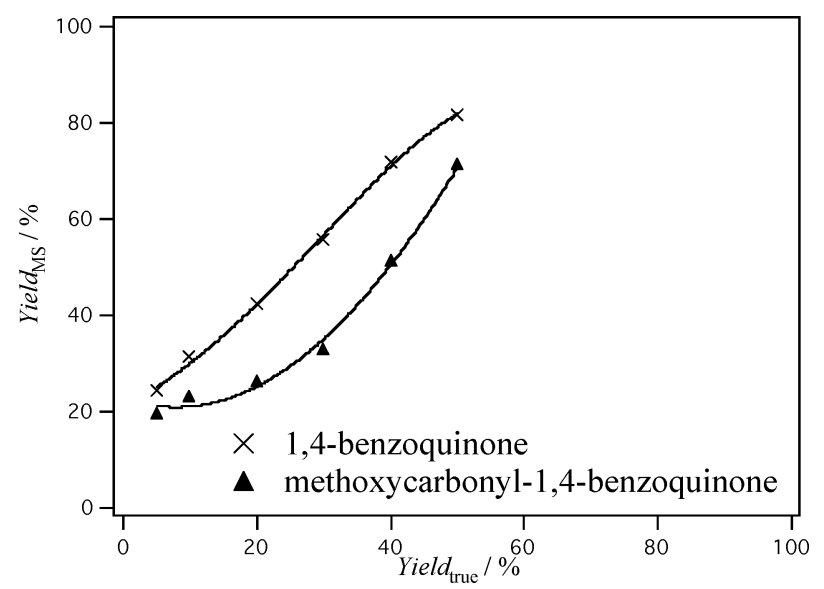

Figure 5. Calibration curves for the MS tagging yield (Yield $\mathrm{MS}_{\text {) }}$ as a function of the bulk yield (Yield ${ }_{\text {true }}$ ) for the reaction of $\beta$-lactoglobulin A with methoxycarbonyl-1,4-benzoquinone and 1,4-benzoquinone. The mixtures were prepared by adding $B O$ equivalent (from 0.05 to 0.5 ) to $50 \mu \mathrm{M}$ of $\beta$-lactoglobulin $\mathrm{A}$. The fitting of the curves gives $Y=613.57+592.61 \exp (-((X-$ $\left.7.8623) /(142.26))^{2}\right)$ and $Y=8.917+77.954 \exp (-((X-61.596) /$ $(45.194))^{2}$ ) for methoxycarbonyl-1,4-benzoquinone and 1,4-benzoquinone, respectively.

$\beta$-lactoglobulin A. Having evaluated the addition rate constant, eq 6 can then be used to determine the local $\mathrm{p} K_{\mathrm{ap}}$ compared to that of L-cysteine. Indeed, we can write assuming that $k_{\text {true }}$ is the same for both the amino acid and the protein:

$$
\frac{k_{\mathrm{P}}}{k_{\text {cys }}}=\frac{10^{\mathrm{p} K_{\mathrm{acys}}-\mathrm{pH}}+1}{10^{\mathrm{p} K_{\mathrm{aP}}-\mathrm{pH}}+1}
$$

where $k_{\text {cys }}$ is the addition rate constant determined with $\mathrm{L}$-cysteine (Table 2) and $\mathrm{p} K_{\mathrm{a}_{\text {cys }}}$ is the thiol $\mathrm{p} K_{\mathrm{a}}$ of $\mathrm{L}$-cysteine. This equation yields a local $\mathrm{p} K_{\mathrm{ap}}$ of 8.8 when taking $\mathrm{p} K_{\mathrm{a}_{\mathrm{cys}}}=8$ for $\mathrm{L}$-cysteine and $\mathrm{pH}=3.3$ (spray medium).

For comparison, we also tagged $\beta$-lactoglobulin A with 1,4hydroquinone and in this case the e-TE\% measured (Table 2) yields a rate constant value of $k_{\mathrm{P}}=105 \mathrm{M}^{-1} \cdot \mathrm{s}^{-1}$. Considering eq 7 and the fixed thiol $\mathrm{p} K_{\mathrm{ap}}$ value of $\beta$-lactoglobulin $\mathrm{A}$ in the medium, eq 8 must be satisfied

$$
\left(\frac{k_{\mathrm{P}}}{k_{\text {cys }}}\right)_{\text {methoxycarbonyl - 1,4- hydroquinone }}=\left(\frac{k_{\mathrm{P}}}{k_{\text {cys }}}\right)_{1,4-\text { hydroquinone }}
$$

This ratio is however found three times larger for 1,4-hydroquinone than for methoxycarbonyl-1,4-hydroquinone showing the role of steric hindrance after consideration of $\mathrm{p} K_{\mathrm{a}}$ effects.

This result clearly shows that the decrease of the tagging rate of $\beta$-lactoglobulin A by methoxycarbonyl-1,4-hydroquinone from the predicted value of $79 \%$ to the experimental value of $26 \%$ does not only result from the thiol increased $\mathrm{p} K_{\mathrm{ap}}$ in the protein but also from other factors. The steric hindrance acting on the EC-tag can be considered to have a relevant influence on the decrease of the kinetics. Indeed, free access of the probe to the cysteine is notably hindered by the protein chain even in denaturing solvents as the $3 \mathrm{D}$ structure is conserved by the presence of disulfide bridges even at low $\mathrm{pH} .{ }^{43,44}$

In conclusion, the low tagging extent e-TE\% observed with $\beta$-lactoglobulin $\mathrm{A}$ is basically associated to kinetic limiting factors linked with the cysteine environment (i.e., the $\mathrm{p} K_{\mathrm{a}}$ value 

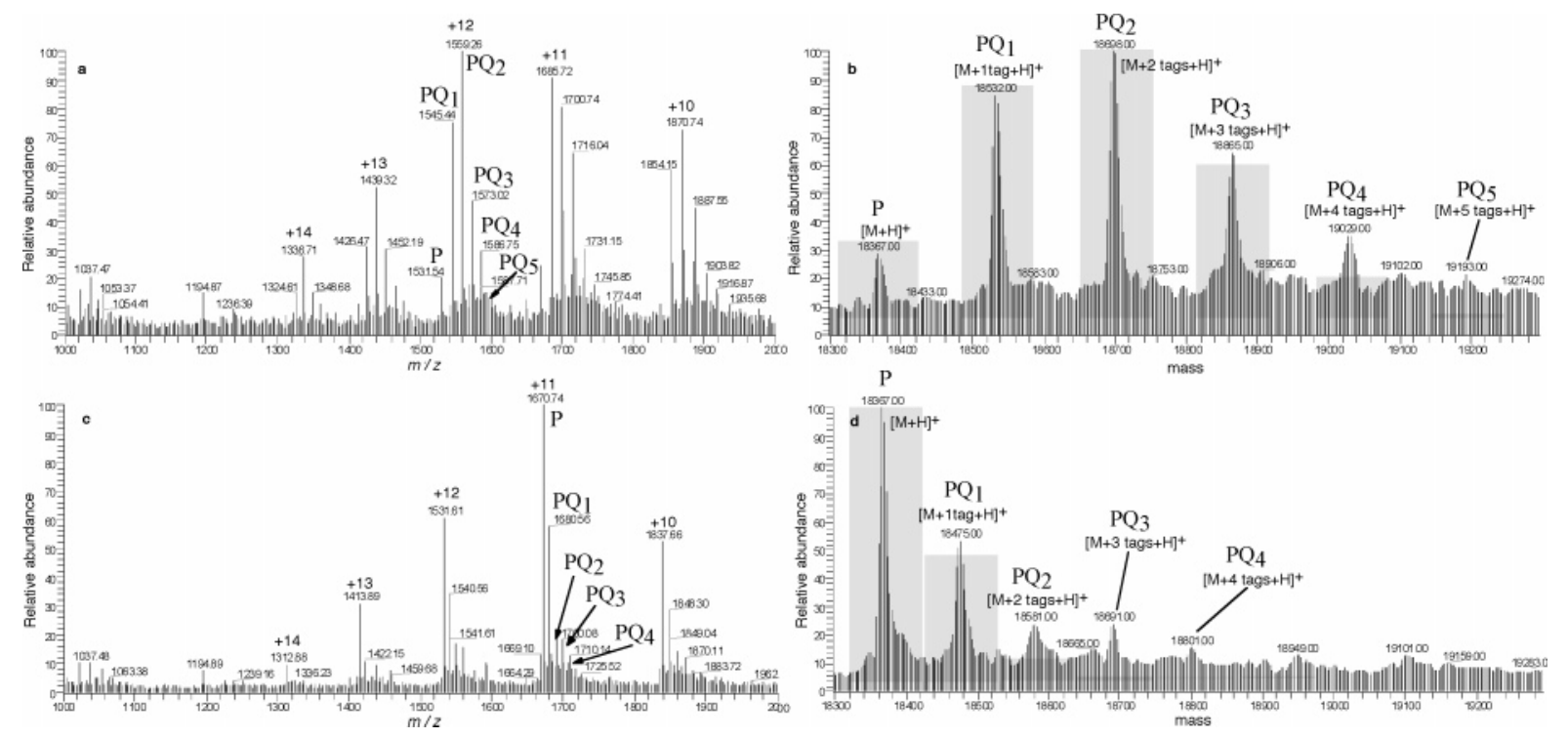

Figure 6. Microspray mass spectra of reduced $\beta$-lactoglobulin A ( $50 \mu \mathrm{M})$ infused with methoxycarbonyl-1,4-hydroquinone (2.5 mM) (a) and 1,4-hydroquinone ( $2.5 \mathrm{mM})$ (c). Deconvolution mass spectra of reduced $\beta$-lactoglobulin $\mathrm{A}(50 \mu \mathrm{M})$ infused with methoxycarbonyl1,4-hydroquinone $(2.5 \mathrm{mM})(\mathbf{b})$ and 1,4-hydroquinone $(2.5 \mathrm{mM})(\mathbf{d})$. Grey bars give the predicted distributions of the species according to the analytical model. $\mathrm{P}$ and $\mathrm{PQ}_{1 \ldots 5}$ indicate respectively the untagged and successively tagged proteins.

and the steric hindrance). The EC-tagging is shown to probe the general thiol reactivity by the mass spectrometric measurement of the extent of the tagging reaction.

2.3. Multi-EC-Tagging of Reduced $\beta$-lactoglobulin A. To explore the effect of steric hindrance, we studied the tagging of $\beta$-lactoglobulin A, but after chemically reducing it. Indeed, the cleavage of the two disulfide bonds of the protein will alter completely the tertiary structure, due to almost complete unfolding of the protein chain. Reduced $\beta$-lactoglobulin A was EC-tagged using methoxycarbonyl-1,4-hydroquinone and 1,4hydroquinone as shown in Figure $6 \mathrm{a}, \mathrm{b}$ and c,d, respectively. As predicted by the analytical kinetic model, methoxycarbonyl1,4-hydroquinone provides clearly a very efficient cysteine labeling when compared to 1,4-hydroquinone. Indeed, the tagging of the five cysteines of reduced $\beta$-lactoglobulin A can be observed as shown in Figure 6b. By comparing mass spectra of reduced and nonreduced forms of the protein, the method gives access to the number of disulfide bonds. Besides, comparison with the kinetic model that fits perfectly (Figure $6 \mathrm{~b}$ and $6 \mathrm{~d}$ ) shows clearly the role of the steric hindrance for the nonreduced protein.

The multi-EC-tagging of proteins by methoxycarbonyl-1,4hydroquinone was further tested with creatine phosphokinase (CK) and reduced insulin. By reduction, insulin splits into two polypeptidic chains. The B-chain contains mainly basic amino acids of the protein, conferring to the polypeptide a higher ionization in the spray medium $\left(\mathrm{MeOH} / \mathrm{H}_{2} \mathrm{O} / \mathrm{AcOH} 50 / 49 / 1\right)$ compared to that of the A-chain which is not detected. ${ }^{45}$ The B-chain of insulin is efficiently EC-tagged by methoxycarbonyl1,4-hydroquinone since the untagged species is no longer observed. The fully tagged product appears greatly enhanced relative to the 1,4-hydroquinone reaction (see Supporting Information Figure S2). CK, which contains four free cysteine residues ${ }^{46}$ is EC-tagged on every residues. As for the previous case, MS gives peaks ranging from the untagged protein to the quadruply tagged protein, thus providing the on-line counting of the cysteine units (Figure 7). The experiments also provide information on the CK structure in the spray medium as under
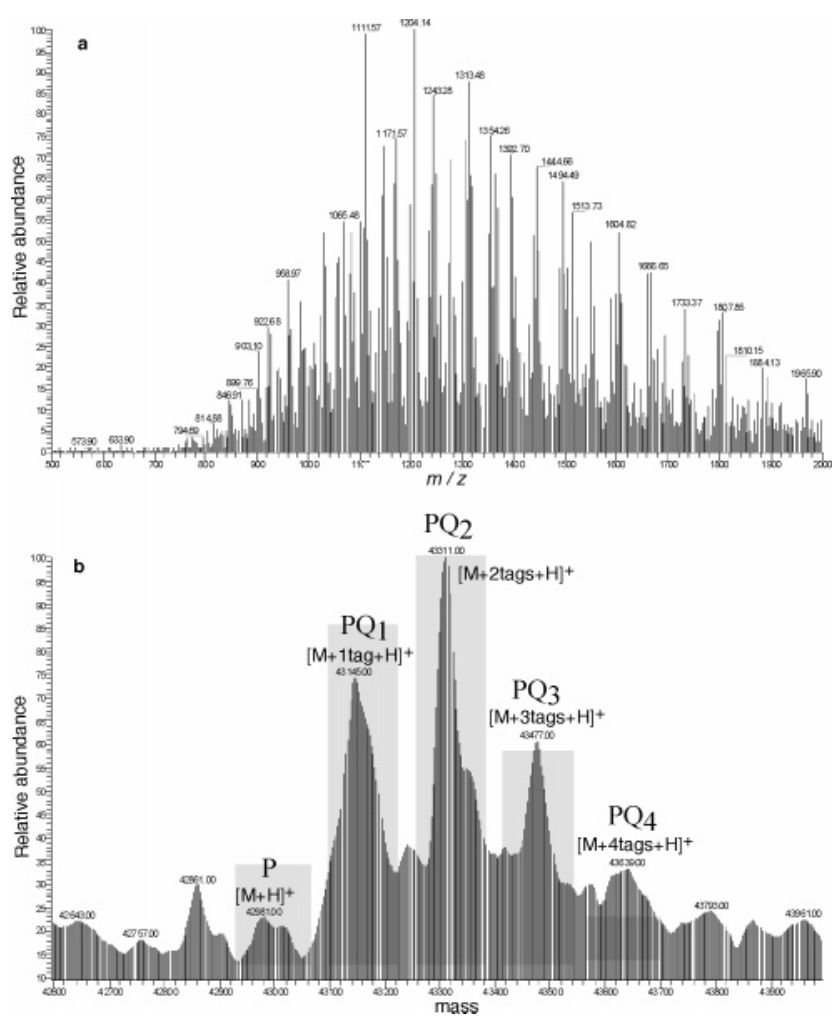

Figure 7. Microspray mass spectrum of creatine phosphokinase $(50 \mu \mathrm{M})$ infused with methoxycarbonyl-1,4-hydroquinone $(2.5$ $\mathrm{mM}$ ) (a). Deconvolution mass spectrum (b). Grey bars give the predicted distribution of the species according to the analytical model. $\mathrm{P}$ and $\mathrm{PQ}_{1 \ldots 4}$ indicate respectively the untagged and successively tagged proteins.

native conditions, only one cysteine unit is accessible for labeling. ${ }^{47}$ These results therefore show that $\mathrm{CK}$ unfolds efficiently in the spray medium $\left(\mathrm{MeOH} / \mathrm{H}_{2} \mathrm{O} / \mathrm{AcOH} 50 / 49 / 1\right)$ to lead to the quadruple tagging reaction. 
This last study demonstrates that methoxycarbonyl-1,4hydroquinone is suitable for the multi-EC-tagging at the protein level. For multi-cysteine-containing unfolded protein, the analytical model fits perfectly well with the apparent tagging (Figures 6 and 7). Whatever the individual cysteine reactivity, the increase of the rates (i.e., $\mathrm{n} k$ ) especially and compensation phenomena between higher and lower reactive thiols reduce the divergence.

\section{Conclusions}

The EC-tagging technique, by nonquantitative labeling, was shown to allow quick detection of cysteine-containing proteins by detection of the specific mass shift(s) corresponding to the marker. An analytical kinetic model taking into account the electrochemical and the chemical steps of the labeling reaction was developed to predict the tagging extent before MS analysis. Validated by comparison with numerically simulated data, the model was shown to fit perfectly well to the EC-tagging experiments on unfolded multi-cysteinyl-containing protein.

In addition, experiments with unmodified proteins and their chemically reduced forms show the strong effect of the cysteine site reactivity on the EC-tagging efficiencies. Chemically reducing the proteins prior to tagging leads both to a successive multi-tagging of the cysteine units liberated by the reduction of disulfide bonds and to an increase in the reaction kinetics. Methoxycarbonyl-1,4-hydroquinone was found to be efficient to tag up to five cysteines in biomacromolecules.

When decoupled from ionization factors eventually induced by the tag, the EC-tagging by methoxycarbonyl-1,4-hydroquinone reveals itself as an useful tool to probe the thiol reactivity of a single-thiol-containing protein. A similar study may be carried out for singly cysteinyl peptides that are by far the most common cysteinyl peptides resulting from proteolytic digestion of the proteome. ${ }^{48}$ For peptides or small molecules presenting negligible steric constraint, the EC-tagging based on mass spectrometric detection could thus directly provide the thiol $\mathrm{p} K_{\mathrm{a}}$ values that are commonly determined by potentiometric and electrophoretic means.

EC-microreactors directly coupled to ESI-MS are attractive tools that can be extensively used for probing the surface accessibilities of specific amino acids. The development of specifically targeted tags will help providing information about the protein microenvironment.

Acknowledgment. Jacques Josserand is thanked for fruitful discussions. The Fonds National Suisse pour la Recherche Scientifique is thanked for financial support through the project "Development of new analytical tools for proteomics" (Grant No. 510.220).

Note Added after ASAP Publication: This manuscript was originally published on the Web $02 / 21 / 2006$ with an error in Scheme 1. "RS" should have been "RSH". The version published on the Web $03 / 01 / 2006$ and in print is correct.

Supporting Information Available: The program for a five-step chemical reaction; the mass spectrum of an equimolar mixture of $\beta$-lactoglobulin A and its tagged analogue shows a signal enhancement for the tagged compound over that of the untagged protein (Figure S1); and the fully tagged insulin product appears greatly enhanced relative to the 1,4-hydroquinone reaction (Figure S2). This material is available free of charge via the Internet at http://pubs.acs.org.

\section{References}

(1) Stewart, A. J.; Blindauer, C. A.; Berezenko, S.; Sleep, D.; Tooth, D.; Sadler, P. J. Role of Tyr84 in controlling the reactivity of Cys34 of human albumin. FEBS J. 2005, 272, 353-362.

(2) Esposito, B. P.; Najjar, R. Interactions of antitumoral platinumgroup metallodrugs with albumin. Coord. Chem. Rev. 2002, 232, $137-149$.

(3) Di Simplicio, P.; Franconi, F.; Frosali, S.; Di Giuseppe, D. Thiolation and nitrosation of cysteines in biological fluids and cells. Amino Acids 2003, 25, 323-339.

(4) Shaked, Z.; Szajewski, R. P.; Whitesides, G. M. Rates of thioldisulfide interchange reactions involving proteins and kinetic measurements of thiol $\mathrm{p} K_{\mathrm{a}}$ values. Biochemistry 1980, 19, 41564166 .

(5) Lutolf, M. P.; Tirelli, N.; Cerritelli, S.; Cavalli, L.; Hubbell, J. A. Systematic modulation of Michael-type reactivity of thiols through the use of charged amino acids. Bioconjugate Chem. 2001, 12, 1051-1056.

(6) de la Mora, J. F.; Van Berkel, G. J.; Enke, C. G.; Cole, R. B.; Martinez-Sanchez, M.; Fenn, J. B. Electrochemical processes in electrospray ionization mass spectrometry-Discussion. J. Mass Spectrom. 2000, 35, 939-952.

(7) Diehl, G.; Karst, U. On-line electrochemistry-MS and related techniques. Anal. Bioanal. Chem. 2002, 373, 390-398.

(8) Rohner, T. C.; Lion, N.; Girault, H. H. Electrochemical and theoretical aspects of electrospray ionisation. Phys. Chem. Chem. Phys. 2004, 6, 3056-3068.

(9) Kertesz, V.; Deng, H. T.; Asano, K. G.; Hettich, R. L.; Van Berkel, G. J. $N$-phenyl-1,4-phenylenediamine and benzidine oxidation products identified using on-line electrochemistry/electrospray Fourier transform mass spectrometry. Electroanalysis 2002, 14, 1027-1030.

(10) Zhang, T. Y.; Palii, S. P.; Eyler, J. R.; Brajter-Toth, A. Enhancement of ionization efficiency by electrochemical reaction products in on-line electrochernistry/electrospray ionization Fourier transform ion cyclotron resonance mass spectrometry. Anal. Chem. 2002, 74, 1097-1103.

(11) Zhang, T. Y.; Brajter-Toth, A. On-line investigation of the generation of nonaqueous intermediate radical cations by electrochemistry/mass spectrometry. Anal. Chem. 2000, 72, 2533-2540.

(12) Deng, H. T.; Van Berkel, G. J. Electrochemical polymerization of aniline investigated using on line electrochemistry/electrospray mass spectrometry. Anal. Chem. 1999, 71, 4284-4293.

(13) Regino, M. C. S.; Brajter-Toth, A. An electrochemical cell for online electrochemistry mass spectrometry. Anal. Chem. 1997, 69, 5067-5072.

(14) Deng, H. T.; Van Berkel, G. J. A thin-layer electrochemical flow cell coupled on-line with electrospray-mass spectrometry for the study of biological redox reactions. Electroanalysis 1999, 11, 857865.

(15) Gamache, P. H.; Meyer, D. F.; Granger, M. C.; Acworth, I. N. Metabolomic applications of electrochemistry/mass spectrometry. J. Am. Soc. Mass Spectrom. 2004, 15, 1717-1726.

(16) Seiwert, B.; Henneken, H.; Karst, U. Ferrocenoyl piperazide as derivatizing agent for the analysis of isocyanates and related compounds using liquid chromatography/electrochemistry/mass spectrometry (LC-EC/MS). J. Am. Soc. Mass Spectrom. 2004, 15, $1727-1736$.

(17) Quirke, J. M. E.; Adams, C. L.; Van Berkel, G. J. Chemical derivatization for electrospray-ionization mass-spectrometry.1. Alkyl-halides, alcohols, phenols, thiols, and amines. Anal. Chem. 1994, 66, 1302-1315.

(18) Quirke, J. M. E.; Hsu, Y. L.; Van Berkel, G. J. Ferrocene-based electroactive derivatizing reagents for the rapid selective screening of alcohols and phenols in natural product mixtures using electrospray-tandem mass spectrometry. J. Nat. Prod. 2000, 63, 230-237.

(19) Van Berkel, G. J.; Asano, K. G. Chemical Derivatization for Electrospray-Ionization Mass-Spectrometry.2. Aromatic and Highly Conjugated Molecules. Anal. Chem. 1994, 66, 2096-2102.

(20) Van Berkel, G. J.; Quirke, J. M. E.; Tigani, R. A.; Dilley, A. S.; Covey, T. R. Derivatization for electrospray ionization mass spectrometry. 3. Electrochemically ionizable derivatives. Anal. Chem. 1998, 70, 1544-1554.

(21) Van Berkel, G. J.; Quirke, J. M. E.; Adams, C. L. Derivatization for electrospray ionization-mass spectrometry. 4. Alkenes and alkynes. Rapid Commun. Mass Spectrom. 2000, 14, 849-858. 
(22) Roussel, C.; Dayon, L.; Lion, N.; Rohner, T. C.; Josserand, J.; Rossier, J. S.; Jensen, H.; Girault, H. H. Generation of mass tags by the inherent electrochemistry of electrospray for protein mass spectrometry. J. Am. Soc. Mass Spectrom. 2004, 15, 1767-1779.

(23) Rohner, T. C.; Rossier, J. S.; Girault, H. H. Polymer microspray with an integrated thick-film microelectrode. Anal. Chem. 2001, 73, 5353-5357.

(24) Rohner, T. C.; Rossier, J. S.; Girault, H. H. On-line electrochemical tagging of cysteines in proteins during nanospray. Electrochem. Commun. 2002, 4, 695-700.

(25) Dayon, L.; Roussel, C.; Prudent, M.; Lion, N.; Girault, H. H. Online Counting of Cysteine Residues in Peptides during Electrospray Ionisation by Electrogenerated Tags and its Application to Protein Identification. Electrophoresis 2005, 26, 238-247.

(26) Dayon, L.; Roussel, C.; Girault, H. H. On-line electrochemical tagging of free cysteines in peptides during nanospray ionisation mass spectrometry: An overview. Chimia 2004, 58, 204-207.

(27) Roussel, C.; Dayon, L.; Jensen, H.; Girault, H. H. On-line cysteine modification for protein analysis: new probes for electrochemical tagging nanospray mass spectrometry. J. Electroanal. Chem. 2004, 570, 187-199.

(28) Carru, C.; Deiana, L.; Sotgia, S.; Pes, G. M.; Zinellu, A. Plasma thiols redox status by laser-induced fluorescence capillary electrophoresis. Electrophoresis 2004, 25, 882-889.

(29) Bourell, J. H.; Clauser, K. P.; Kelley, R.; Carter, P.; Stult, J. T. Electrospray-ionization mass-spectrometry of recombinantly engineered antibody fragments. Anal. Chem. 1994, 66, 2088-2095.

(30) Abdou, W. M.; ElKhoshnieh, Y. O.; Kamel, A. A. The reactions of 2,6-di-tert-butyl-1,4-benzoquinone with triphenyl-phosphine, -arsine and -stibine and their oxides. J. Chem. Res.-S 1996, 326327.

(31) Crescenzi, O.; Prota, G.; Schultz, T.; Wolfram, L. J. The reaction of cysteine with 1,4-benzoquinone - a revision. Tetrahedron 1988, 44, 6447-6450.

(32) Rossier, J. S.; Ferrigno, R.; Girault, H. H. Electrophoresis with electrochemical detection in a polymer microdevice. J. Electroanal. Chem. 2000, 492, 15-22.

(33) Girault, H. H. Analytical and Physical Electrochemistry, 1st ed.; EPFL Press: Lausanne, 2004, pp 285-286.

(34) Unwin, P. R.; Compton, R. G. Comprehensive Chemical Kinetics Eds.: Compton, R. G., Hammet, A., Eds; Elsevier: Amsterdam, 1989; Vol. 29, pp. 173-193.

(35) Levich, V. G. Physicochemical Hydrodynamics; Prentice-Hall: Englewood Cliffs, 1962; pp. 112-116.

(36) Amaro, A. R.; Oakley, G. G.; Bauer, U.; Spielmann, H. P.; Robertson, L. W. Metabolic activation of PCBs to quinones: Reactivity toward nitrogen and sulfur nucleophiles and influence of superoxide dismutase. Chem. Res. Toxicol. 1996, 9, 623-629.
(37) Roussel, C.; Rohner, T. C.; Jensen, H.; Girault, H. H. Mechanistic aspects of on-line electrochemical tagging of free L-cysteine residues during electrospray ionisation for mass spectrometry in protein analysis. Chem. Phys. Chem. 2003, 4, 200-206.

(38) Dayon, L.; Josserand, J.; Girault, H. H. Electrochemical multitagging of cysteinyl peptides during microspray mass spectrometry: numerical simulation of consecutive reactions in a microchannel. Phys. Chem. Chem. Phys. 2005, 7, 4054-4060.

(39) Ren, D. Y.; Julka, S.; Inerowicz, H. D.; Regnier, F. E. Enrichment of cysteine-containing peptides from tryptic digests using a quaternary amine tag. Anal. Chem. 2004, 76, 4522-4530.

(40) Jencks, W. P.; Carriuolo, J. Reactivity of nucleophilic reagents toward esters. J. Am. Chem. Soc. 1960, 82, 1778-1786.

(41) Bizzozero, O. A.; Bixler, H. A.; Pastuszyn, A. Structural determinants influencing the reaction of cysteine-containing peptides with palmitoyl-coenzyme A and other thioesters. Biochim. Biophys. Acta-Protein Struct. Mol. Enzymol. 2001, 1545, 278288.

(42) Grzybowski, B. A.; Anderson, J. R.; Colton, I.; Brittain, S. T. Shakhnovich, E. I.; Whitesides, G. M. Modeling the kinetics of acylation of insulin using a recursive method for solving the systems of coupled differential equations. Biophys. J. 2000, 78, $652-661$.

(43) Uhrinova, S.; Smith, M. H.; Jameson, G. B.; Uhrin, D.; Sawyer, L.; Barlow, P. N. Structural changes accompanying $\mathrm{pH}$-induced dissociation of the beta-lactoglobulin dimer. Biochemistry 2000 , 39, 3565-3574.

(44) Babu, K. R.; Moradian, A.; Douglas, D. J. The methanol-induced conformational transitions of beta-lactoglobulin, cytochrome $c$, and ubiquitin at low $\mathrm{pH}$ : A study by electrospray ionization mass spectrometry. J. Am. Soc. Mass Spectrom. 2001, 12, 317328.

(45) Stephenson, J. L.; Cargile, B. J.; McLuckey, S. A. Ion trap collisional activation of disulfide linkage intact and reduced multiply protonated polypeptides. Rapid Commun. Mass Spectrom. 1999, 13, 2040-2048.

(46) Wang, H. R.; Bai, J. H.; Zheng, S. Y.; Wang, Z. X.; Zhou, H. M. Ascertaining the number of essential thiol groups for the folding of creatine kinase. Biochem. Biophys. Res. Commun. 1996, 221 $174-180$

(47) Tanaka, N.; Tonai, T.; Kunugi, S. Site-specific modification of rabbit muscle creatine kinase with sulfhydryl-specific fluorescence probe by use of hydrostatic pressure. Biochim. Biophys. Acta-Protein Struct. Mol. Enzymol. 1997, 1339, 226-232.

(48) Lion, N. PhD thesis, Ecole Polytechnique Fédérale de Lausanne, in preparation.

PR050365O 